To the Editor,

\title{
Nirogi Paadha: a step forward for the Sri Lankan Diabetic
}

\author{
Sri Lanka Journal of Diabetes, Endocrinology and Metabolism 2013; 3: 112-113
}

The increased risk of wounding coupled with poor healing and amputation that involves diabetic feet is well known (1). Based on recent epidemiologic surveys in Sri Lanka, we are dealing with approximately 1.5 to 2 million diabetics as of now (2). With an annual rate of $5 \%$, we are likely to be dealing with approximately 100,000 foot ulcers in diabetics every year (3). The resultant amputations, impairment of quality of life and cost must be enormous, although not quantified in Sri Lanka. The current focus on improving life expectancy alone is not sufficient. It is time we also pay due attention to quality of life issues; thus a strong commitment toward amputation prevention in Sri Lanka. Diabetes is the main cause for non traumatic amputations and is also a contributor/marker of premature death (4). Hence there is an urgent need to focus on diabetic limb salvage in Sri Lanka.

The primary challenge in diabetic limb salvage involves prevention of wounding in the first place and when that fails, healing without progressing to amputation; thereby preserving independent ambulation and quality of life. But is this possible and if so how?

The Nirogi Paadha project of the Diabetes Prevention Task Force of the Sri Lanka Medical Association together with Sri Lankan League for the Prevention of Diabetic Foot Amputation and Endocrine Society of Sri Lanka have taken on this challenge. They need the support of all sectors of our health care system in order to succeed.

Success demands an understanding of what is going on with answers to the questions: "how" and "why".

The key areas we need to recognize are:

1. Medical knowledge and skills

2. Implementation

3. Patient compliance issues and

4. The need to audit

No one doubts the need for knowledge and skills. Transfer of knowledge to medical officers and other members of the healthcare team on diabetic angiopathy, neuropathy and immunopathy with the complex interactions between these mechanistic factors is ongoing and must be sustained. But this alone is not sufficient. Non application of this knowledge into clinical practice makes the understanding worthless. In the words of J. A.
Lindsay, "for one mistake made for not knowing, ten mistakes are made for not looking”. The problem does not end here. Having acquired the knowledge and applied it, the next stumbling block is non compliance by the patient. Adherence to the recommended diet, medication and physical activity program to achieve and maintain optimum glycaemic status, reduce other metabolic risks, and the avoidance of tobacco is a constant challenge. Poor compliance with use of appropriate footwear, daily foot inspection, immediate reporting of a fresh change and regular follow up of high risk feet is a global issue (5). We therefore need to evolve a home-grown system to overcome these problems amidst our resource limited structure. Finally we need to appreciate the necessity to audit. Data on the process and outcomes are essential to justify and direct any program, and this is no exception. The initiative on 'quality and safety' in the Ministry of Health will have the opportunity to contribute in this respect.

What actually needs to be done? Patient education, assessment with risk categorization, provision of footwear, removal of callus, management of infection, ensuring healing and moreover maintenance of the healed state is the list in a nutshell. Nirogi Paadha project has developed the care plan covering all of the above in order to standardize and optimize the diabetic foot service in Sri Lanka. What is striking here is that no one person can deliver such a wide array of services to a patient. Many people will have to work together in a coordinated fashion towards the common goal of amputation prevention Nirogi Paadha. A limb salvage team in Sri Lanka! After all, we have the necessary members in all our hospitals, i.e. medical, surgical, nursing and others, but no teams. The Nirogi program is attempting to focus on these issues and attempts to introduce a team concept at hospital level and later bring in community healthcare workers to further enhance compliance, reduce complications and cost and most importantly reduce the workload on hospitals.

Finally we need to be able to offer appropriate footwear to protect insensate feet and it is noteworthy that the project has collaborated with DSI group of companies to provide general footwear at an affordable price throughout the country. This is in parallel with arrangements for training of Orthotists to provide for specialized custom-made footwear in collaboration with the Sri Lankan Society of Prosthetics and Orthotics based at the Ragama Rehabilitation Hospital. 
We must remember that success is not the destination but a journey and what matters most is where we are and the direction in which we are moving. In our attempts to salvage the diabetic foot, the destination is clear, the path is known and the journey has just begun. But the road ahead is full of obstacles and needs the support of all in order to reach the destination, Nirogi Paadha.

Your attention is drawn to the Practice Guidelines developed by all stakeholders and officially launched in July 2013.

\section{References}

1. Pendsey SP. Understanding diabetic foot. Int $J$ Diabetes Dev Ctries 2010; 30(2): 75-79.
2. Katulanda P, Constantine GR, Mahesh JG, Sheriff R, Seneviratne RD, Wijeratne S, Wijesuriya M, McCarthy MI, Adler AI, Matthews DR. Prevalence and projections of diabetes and pre-diabetes in adults in Sri Lanka - Sri Lanka Diabetes, Cardiovascular Study (SLDCS). Diabet Med 2008; 25(9):1062-9.

3. Sambamoorthi U, Tseng C, et al. Initial Non-traumatic Lower-Extremity Amputations Among Veterans With Diabetes. Med Care 2006; 44(8): 779-87.

4. Andrew JM, Jude EB. Therapeutic Footwear in Diabetes: The good, the bad, and the ugly? Diabetes Care 2004; 27 : 1832-3.

5. Shaw JE, van Shie CHM, Carrington AL, Abbott CA, Boulton AJM. An analysis of the foot in diabetic neuropathy. Diabetes Care 1998; 21: 1955-9.

\section{Mandika Wijeyaratne}

Professor in Surgery, University of Colombo, Honorary Consultant, National Hospital of Sri Lanka. 